\title{
Economic Man and the Consumption of Addictive Goods: The Case of Two Goods
}

\author{
Linda Andersson*and Mikael Bask ${ }^{\dagger \ddagger}$ \\ Department of Economics, Umeå University \\ SE-901 87 Umeå, Sweden \\ Maria Melkersson ${ }^{\S}$ \\ Swedish Institute for Growth Policy Studies \\ SE-831 40 Östersund, Sweden
}

October 6, 2003

\begin{abstract}
It is well-known that cigarette smoking and the use of other addictive goods is harmful to health. Still, some people smoke cigarettes and drink alcohol in their daily life. The consumption of addictive goods seems, therefore, to be the anti-thesis of rational behavior. In this paper, however, it is demonstrated that a rational individual, in the sense that he maximizes his well-being while anticipating the future consequences of his choices, may in fact choose to consume addictive goods. Specifically, the two-good extension of the rational addiction model is demonstrated and related to relevant policy questions. For instance, should one encourage the use of smokeless tobacco in smoking cessation programs? According to the empirical results, the answer is no. Further, should one discourage smoking by increasing the tax on cigarettes? Again, the answer is no.
\end{abstract}

Keywords: Alcohol, Bootlegging, Cigarette Smoking, Complements, Rational addiction, Substitutes.

JEL-code: I1.

\footnotetext{
* Telephone: +46-90-786 95 85, E-mail: linda.andersson@econ.umu.se

$\dagger$ Telephone: +46-90-786 78 77, E-mail: mikael.bask@econ.umu.se

$\ddagger$ Corresponding author.

$\S$ Telephone: +46-63-16 66 17, E-mail: maria.melkersson@itps.se
} 


\section{Introduction}

In modern society, it is well-known that cigarette smoking, excessive use of alcohol, and the use of cocaine, heroin and marijuana, is harmful to health. These goods are not only a hazard to health, they are also addictive, sometimes strongly addictive. Still, some people smoke cigarettes and use other similarly addictive goods in their daily life. The consumption of addictive goods seems, therefore, to be the anti-thesis of rational behavior. Since health problems associated with addictive behavior are a natural research topic for medical doctors, psychologists, and sociologists, the question is what the value added would be to study the demand for addictive goods from an economic perspective.

Economics is the study of how individuals and societies choose to use the scarce resources that nature and previous generations have provided, in order to satisfy their unlimited wants. Thus, the core of economics is to find a deeper understanding of human behavior within a social framework. An individual living in the "world of economics" is usually referred to as economic man, or homo economicus. He earns his living by being engaged in productive activities, and strives to satisfy his wants by consuming goods and services.

Basically, there are three premises that underlie the behavior of economic man. Firstly, the amount of pleasure he derives from goods and services consumed is determined by his preferences. Secondly, even if the wants of economic man are unlimited, he faces constraints on his choices. Thirdly, economic man maximizes his well-being from consumption subject to these constraints. These three premises describe, in a nutshell, the economic approach to human behavior. Since economic man appears to be a rational individual, it is intriguing to ask why a rational individual would choose to consume an addictive good such as cigarettes or alcohol. Is there really such a thing as rational addiction?

Drawing directly from the definition of economics, the contribution of studying the consumption of addictive goods from an economic perspective is at least twofold. Firstly, understanding the demand for various goods, in our case addictive goods, is a central aspect in economics. Once we understand the driving forces behind the demand for these types of goods, it is possible to develop policy recommendations on how to affect, and maybe limit, the consumption. Secondly, health problems associated with the consumption of addictive goods lead to substantial costs for society. Hence, society needs to allocate resources to this matter, resources that could have been used elsewhere.

When modelling the demand for addictive goods, the most widely used framework is the rational addiction model proposed in the seminal paper by Becker and Murphy (1988). According to Becker and Murphy (1988), consumption of addictive goods, even strongly addictive goods, can be classified as rational behavior since the addicted individual strives to maximize his well-being subject to the constraints he faces. Even the addicted individual has a time horizon that spans beyond the present time period, and, therefore, weighs both the present and the future into his consumption decision. The latter distinguishes rational behavior from myopic behavior, where the present consumption decision is made independently of the future. 
The rest of the paper is organized as follows. The rational addiction model is presented in Section 2. The traditional one-good case is first discussed, and then extended to include two addictive goods. Section 3 contains a discussion of various results found in the empirical literature on the consumption of more than one addictive good. Firstly, we consider the consumption of two goods being addictive through the same substance, nicotine, namely cigarettes and smokeless tobacco. Secondly, the presence of bootleg activity provides competition for the legal market. We discuss how empirical research deals with bootleg activity and how the presence of an illegal market affects the consumption of the addictive good. Thirdly, there is a wide range of addictive goods available for an individual nowadays. We overview the empirical results of the interdependence between some of these goods. The paper concludes, in Section 4, with a discussion of the usefulness of economic theory in understanding the consumption pattern regarding addictive goods.

\section{Rational addiction}

\subsection{One addictive good}

To begin with, let us assume that there is only one addictive consumption good. Since it is well-known that cigarette smoking is harmful to health, and that it is difficult to stop smoking as nicotine is a highly addictive substance, we may think of cigarettes as the single addictive good. Then, a consumer is said to be addicted to smoking, if an increase in past smoking causes present smoking to rise. This behavior is usually assumed to involve two things, reinforcement and tolerance. Reinforcement means that an increase in past smoking increases the craving for smoking today, and has the important implication that the consumption of cigarettes at different time periods in time are complements. On the other hand, tolerance means that the satisfaction of present smoking is lower when past smoking is greater.

To fix ideas, let $U[t]$ be a function that measures the instantaneous utility at time $t$ of smoking cigarettes and consuming a bundle of non-addictive goods, which are denoted by $c[t]$ and $y[t]$, respectively. Moreover, $F[t]$ is a habit stock that measures the degree of addiction at time $t$, which means that it can be interpreted as a stock of nicotine dependence. A simple formulation of the habit stock is

$$
F[t]=c[t-1]
$$

i.e., the habit stock in the present period is equal to the amount of smoking in the previous period. Then, we may write the instantaneous utility function in the following way: ${ }^{1}$

$$
U[t]=U(c[t], F[t], y[t])
$$

where the utility function is a measure of the degree of well-being for a representative consumer.

\footnotetext{
1 Of course, a more realistic way to model the instantaneous utility is to assume that present utility is influenced by the amount of smoking that has taken place in all previous periods. The key results, however, are not affected by our simplification.
} 
Now, how is the instantaneous utility affected by a change in smoking, present as well as past smoking? Firstly, since smoking relaxes the user through the effect of its nicotine content, it is assumed that smoking one extra cigarette today increases the instantaneous utility. Though, the rate of increase in utility decreases with the amount of cigarettes smoked. For example, the increase in utility of smoking six cigarettes instead of five is larger than smoking eleven cigarettes instead of ten. Thus, the marginal utility derived from smoking is assumed to be positive, $U_{c}>0$, but at a decreasing rate, $U_{c c}<0$. The same holds for the bundle of non-addictive goods, $U_{y}>0$ and $U_{y y}<0$.

Secondly, due to tolerance, the habit stock affects instantaneous utility negatively, $U_{F}<0$, and it is also assumed to do this at an increasing rate, $U_{F F}<0$. Thus, the satisfaction of present smoking is lower when past smoking is greater, and the rate of decrease in satisfaction increases with past smoking. For example, smoking eleven cigarettes instead of ten in the previous period (recall that the habit stock in the present period is equal to the amount of smoking in the previous period, see (1)), has a stronger negative effect on utility than smoking six cigarettes instead of five. Thirdly, because of reinforcement, an increase in past smoking increases the craving for smoking today. Thus, past smoking increases the marginal utility of present smoking, $U_{c F}>0$. Finally, consumption of the bundle of non-addictive goods is assumed to have no effect on smoking, $U_{c y}=U_{F y}=0$.

Since the consumer's consumption choices are constrained by the consumer's wealth and by the prices of cigarettes and the bundle of non-addictive goods, the consumer faces the following budget constraint:

$$
\sum_{t=1}^{\infty}(1+r)^{-t}(p[t] c[t]+y[t])=W,
$$

where $r>0$ is the constant discount rate, $p[t]$ is the money price of cigarettes, and $W$ is the consumer's wealth. The money price of the bundle of non-addictive goods is the numeraire. As can be seen in (3), it is not only the price of cigarettes today and the consumer's wealth that constitute the budget constraint, but also the future stream of (discounted) prices puts a constraint on the consumer's consumption choices. This is because the consumer is forward-looking in his behavior, and, therefore, anticipates the future consequences of his consumption choices.

The objective for the consumer is to choose $\{c[t]\}_{1}^{\infty}$ and $\{y[t]\}_{1}^{\infty}$ to maximize utility:

$$
\max _{c[t], y[t]} \sum_{t=1}^{\infty}(1+\sigma)^{-t} U(c[t], F[t], y[t]),
$$

subject to the budget constraint in (3), the formulation of the habit stock in (1), and given $c[0]$ and $y[0]$, where $\sigma>0$ is the constant rate of time preference. The solution to the consumer's problem gives the time paths for cigarette smoking as well as the consumption of the bundle of non-addictive goods. In other words, it is possible to derive demand equations for these goods. Since the focus in this paper is on addictive goods, we will only derive the demand equation for cigarettes.

A standard technique used to derive demand equations is to approximate the instantaneous utility function in the neighborhood of steady-state by a quadratic function in the arguments. Thus, if we 
substitute the appropriate quadratic utility function into the consumer's problem and assume perfect capital markets, i.e., $\sigma=r$, the following demand equation for cigarettes (or any addictive good) can be derived: ${ }^{2}$

$$
c[t]=\beta_{0}+(1+r) \beta_{1} c[t-1]+\beta_{1} c[t+1]+\beta_{2} p[t] .
$$

Note that the parameter for lagged smoking equals the effect of lead smoking multiplied by $1+r$. Testing this restriction has, in the literature, been used as a "test" of the rational addiction hypothesis, i.e., it has been taken as evidence supporting the model, given that the implied discount rate is reasonable.

One drawback of the rational addiction model is that it does not explicitly explain why some individuals become addicted in the first place. According to Becker and Murphy (1988), the decision to start using a harmful good, such as cigarettes, may be triggered by a stressful situation like tension at work or a painful break-up. Another gateway into addiction is peer pressure. However, once an individual has become addicted, the model provides a useful tool to analyze the demand for the addictive good.

Despite the shortcomings, the rational addiction model is today accepted among economists. This has to do with the theoretical rigor of the model, as well as the empirical success (Ferguson, 2000).

\subsection{Two addictive goods}

Now, let us turn to the case of two addictive consumption goods. We do so by extending the example in the previous subsection to include a possible substitute to cigarettes. Since cigarette smoking is harmful, reducing smoking would benefit both individuals and society. However, it is known to be difficult to stop smoking since nicotine is a highly addictive substance, and relapses are common among smokers who try to quit. We examine whether there are any attractive alternatives to cigarettes for a smoker who wants to quit, other than completely abstaining.

One product that differs from pharmaceutical nicotine replacements, such as gum and patches, is the Swedish moist snuff, locally known as snus. This is an important nicotine source in addition to cigarettes in Sweden. ${ }^{3}$ Snus probably offers a much better substitute for cigarettes than patches and other nicotine replacement therapy medications since the way in which snus delivers nicotine is closer to that of cigarettes. Cigarettes and snus both give the user a "rush" of nicotine which, for example, nicotine gum and patches do not. Moist snuff has also been used with success in smoking cessation programs, although not in Sweden (Tilashalski et al., 1998).

Therefore, let $U[t]$ be a function that measures the instantaneous utility at time $t$ of smoking cigarettes,

\footnotetext{
2 Note that the assumption of perfect capital markets, in combination with perfect foresight (as we have in our model), implies that the representative consumer can borrow and lend money freely, i.e., consume future (known) income today and save current income for the future. Therefore, we do not include income in our model, but instead the present value of wealth. The exclusion of income is further motivated by the fact that the instantaneous utility function in the neighborhood of steady-state is approximated by a quadratic function in the arguments, which implies that the first-order conditions are linear, and, thus, that the income distribution will not affect the solution to the maximization problem. This also motivates the use of a representative consumer for the aggregate cigarette market.

3 A recent Swedish survey found that 15 percent of men (only) smoke daily, 18 percent (only) take snus, and 2 percent are mixed users. For women, the corresponding figures are 22 percent smokers, 1 percent snus-takers, and practically no mixed users (Melkersson, 2002).
} 
taking snuff and consuming a bundle of non-addictive goods, which are denoted by $c[t], s[t]$ and $y[t]$, respectively. Moreover, $G[t]$ and $H[t]$ are habit stocks that measure the degree of addiction at time $t$. A simple formulation of the habit stocks is

$$
\left\{\begin{array}{l}
G[t]=c[t-1]+\delta s[t-1] \\
H[t]=(1-\delta) s[t-1]
\end{array},\right.
$$

where $0 \leq \delta \leq 1$. Two extremes are obtained by setting $\delta=0$, which is the case of two separate habit stocks, and by setting $\delta=1$, which is the case of a common habit stock. The latter case assumes that cigarettes and snus are perfect substitutes. The justification for two habit stocks is that there are social and psychological habits connected with one particular nicotine source, and this source may not be switched without certain adjustment costs (Suranovic et al., 1999).

We may write the instantaneous utility function in the following way:

$$
U[t]=U(c[t], s[t], G[t], H[t], y[t])
$$

As in the previous subsection, the marginal utility derived from cigarette smoking is assumed to be positive, $U_{c}>0$, but at a decreasing rate, $U_{c c}<0$. The same holds for snus, $U_{s}>0$ and $U_{s s}<0$, and the bundle of non-addictive goods, $U_{y}>0$ and $U_{y y}<0$. Due to tolerance, the habit stocks affect utility negatively, $U_{G}<0$ and $U_{H}<0$, and they are also assumed to do this at an increasing rate, $U_{G G}<0$ and $U_{H H}<0$. Because each good is reinforced separately, $U_{c G}>0, U_{s G}>0$ and $U_{s H}>0 .^{4}$ Furthermore, it is reasonable to believe that if greater consumption of snus makes it easier to stay away from smoking or to stop smoking completely, then it is necessary that $U_{c s}<0$ and $U_{G H}<0$. However, if snus consumption instead reinforces smoking, we obtain $U_{c s}>0$ and $U_{G H}>0$. Finally, consumption of the bundle of non-addictive goods is assumed to have no effect on cigarette smoking nor taking snuff, i.e., $U_{c y}=U_{s y}=U_{G y}=U_{H y}=0$.

Since the consumer's consumption choices are constrained by the consumer's wealth and by the prices of cigarettes, snus and the bundle of non-addictive goods, the consumer faces the following budget constraint:

$$
\sum_{t=1}^{\infty}(1+r)^{-t}\left(p_{c}[t] c[t]+p_{s}[t] s[t]+y[t]\right)=W,
$$

where $p_{c}[t]$ and $p_{s}[t]$ are money prices of cigarettes and snus, respectively. As in the previous subsection, the money price of the bundle of non-addictive goods is the numeraire. The objective for the consumer is to choose $\{c[t]\}_{1}^{\infty},\{s[t]\}_{1}^{\infty}$ and $\{y[t]\}_{1}^{\infty}$ in order to maximize utility:

$$
\max _{c[t], s[t], y[t]} \sum_{t=1}^{\infty}(1+\sigma)^{-t} U(c[t], s[t], G[t], H[t], y[t]),
$$

subject to the budget constraint in (8), the formulation of the habit stocks in (6), and given $c[0], s[0]$ and $y[0]$.

\footnotetext{
${ }^{4}$ Note that the level of $U_{c H}$ is assumed to be independent of past smoking. The reason is that the habit stock for snus, $H[t]$, does not depend on cigarette smoking.
} 
If we substitute the appropriate quadratic utility function into the consumer's problem and assume perfect capital markets, i.e., $\sigma=r$, the following demand equations for cigarettes and snus (or any addictive goods) can be derived: ${ }^{5}$

$$
c[t]=\beta_{10}+(1+r) \beta_{11} c[t-1]+\beta_{11} c[t+1]+\beta_{12} s[t-1]+\beta_{13} s[t]+\beta_{14} s[t+1]+\beta_{15} p_{c}[t],
$$

and

$$
s[t]=\beta_{20}+(1+r) \beta_{21} s[t-1]+\beta_{21} s[t+1]+\beta_{22} c[t-1]+\beta_{23} c[t]+\beta_{24} c[t+1]+\beta_{25} p_{s}[t] .
$$

Note that the parameters for lagged cigarette consumption as well as lagged snus consumption are equal to the effect of lead consumption of the same good multiplied by $1+r$. As mentioned in the previous subsection, testing these restrictions have been used as "tests" of the rational addiction hypothesis. If we assume a common habit stock for cigarettes and snus, i.e., $\delta=1$ in (6), lagged cigarette smoking has the same effect as lagged snus consumption on current consumption, i.e., $(1+r) \beta_{11}=\beta_{12}$ and $(1+r) \beta_{21}=\beta_{22}$. Thus, we can test the hypothesis of a common habit stock for cigarettes and snus.

The demand equations for cigarettes and snus nest several different behaviors. A non-addicted consumer responds only to information in the current period, which means that the parameters for those variables which correspond to the past and the future are zero. An addicted but myopic consumer also responds to past information, but an addicted consumer who is also forward-looking responds to past, current, and future information.

The long-run demand elasticities are of interest since these elasticities give a measure of the response, between steady-states, to a permanent change in price. As the model consists of two goods, cross-price elasticities, which indicate the response in demand for one of the goods to a change in the price of the other good, may be derived and estimated. Depending on the signs of the cross-price elasticities, it is possible to decide whether snus-taking contributes to a decrease or an increase in smoking. Thus, a positive cross-price elasticity indicates that snus and cigarettes are substitutes, while a negative sign indicates complementarity between the two goods. ${ }^{6}$

\section{What can we learn from empirical research?}

Initially, the empirical literature focused on the study of a single addictive good. The strong holding of the tobacco industry has made the relationship between the price and consumption of tobacco, primarily cigarettes, a natural focal point for research. The results show that the rational addiction model is useful when studying the consumption of cigarettes in the U.S. Studies using time-series data have found that the own-price elasticity, which shows how consumption of the good reacts to a small change in its own price, is centered around -0.40 . This is generally in accordance with results on individual-level data. The

\footnotetext{
5 See Bask and Melkersson (2003c) for a derivation of the demand equations as well as a derivation of the parameter signs.

6 See Bask and Melkersson (2003c) for a derivation of the long-run demand elasticities.
} 
interested reader can turn to the comprehensive review of the literature by Chaloupka and Warner (2000) for a rich discussion. The literature on alcohol demand is similarly reviewed by Cook and Moore (2000).

As the empirical literature has evolved, there has been an increased interest in the relationship between two or more addictive consumption goods, where various combinations of addictive goods have been studied. Our attempt is not to offer a full review, but rather, hopefully, to give the reader a flavor of what the empirical economic literature offers. Table 1 summarizes the results found by the below mentioned research on whether various addictive consumption goods are found to be substitutes or complements to one another.

\subsection{How are smokeless tobacco and cigarettes related?}

Bask and Melkersson (2003c) take the rational addiction theory to the data with the aim to answer the question of whether smokeless tobacco, or more specifically snus, can be useful in smoking cessation programs. The authors use Swedish time-series data for the period 1964-1997 to estimate the model developed in Section 2.2, and find that consumption of both cigarettes and snus are negatively and significantly related to their own prices. The results also give some support to the rational addiction hypothesis, i.e., that there is a positive effect on the level of current consumption of both the lagged and lead consumption of the same good. Although both cigarettes and snus are addictive through nicotine, it appears as if the two goods do not generate a common habit stock. The long-run cross-price elasticities are negative, which indicates that using more snus contributes to increased smoking. The conclusion of this exercise is that even if snus-taking is less harmful to health than cigarette smoking, it is not advisable to encourage its use in smoking cessation programs.

Using data from the 1985 U.S. Current Population Survey (CPS), Ohsfeldt et al. (1997) find that a high tax on cigarettes, increasing the total cigarette price, leads to a lower consumption of the good, while it is associated with a high consumption of snuff and other smokeless tobacco, at least among males. However, the data show no evidence that state law restrictions on smoking would affect the use of smokeless tobacco.

\subsection{How to deal with bootleg activity}

There is a vast literature in economics on cigarette demand, and there are many empirical papers based on individual-level data, panel data and time-series data, but relatively few of these studies take into account the parallel market for bootleg cigarettes (Chaloupka and Warner, 2000). Neglecting the relationship between the two cigarette markets hides the fact that price sensitivity is not entirely a consequence of people smoking less or quitting altogether when prices increase, but rather is partly explained by the fact that bootleg cigarettes are substituted for some legal cigarettes. From the point of view of policy implications, it is therefore crucial to include the markets for both legal and bootleg cigarettes in the analysis. 
The market for bootleg cigarettes has been incorporated into the literature on demand for legal cigarettes in different ways. Using time-series data, the by far most common approach is the one used by Becker et al. (1994), Meier and Licari (1997), Showalter (1999), and Sung et al. (1994), who all use U.S. state-level data. In order to capture incentives for smuggling between states, one or several bootleg incentive indices are included, where these indices are constructed from price differentials (tax differentials) between states. For example, Becker et al. (1994) use three different incentive indices; incentives for long-distance smuggling from tobacco producing states, for short-distance export smuggling to adjacent states, and from short-distance import smuggling, respectively. This approach to handling bootlegging is, of course, not appropriate for a small country with homogeneous prices and taxes, and where the inflow of smuggled cigarettes comes from abroad only.

The tax differentials between the U.S. and Canada have been studied by several researchers (see the review by Chaloupka and Warner, 2000). One example is Galbraith and Kaiserman (1997), who use Canadian time-series data. The authors claim that they have accurate information on the total amount of bootleg cigarettes entering Canada, and simply add legal and bootleg consumption to gain a measure of total consumption. The assumption behind this simplification is that the export of Canadian cigarettes is small and foreign demand for these cigarettes is only marginal. The authors assume that all exported cigarettes will return to Canada in the form of bootleg cigarettes. However, such a simplification is obviously a very special case and is not generalizable to all countries.

Further, van Ours (1995) shows how information on confiscated bootleg goods can be used when modelling demand in the legal market. In a paper on demand for opium, he uses the captured illegal opium as a proxy for the size of the illegal opium market in Indonesia during the 1920s and 1930s.

In all of the papers mentioned above, the inclusion of bootlegging is not based on any specific theoretical foundations. Using the multiple-commodity extension of the rational addiction model, as described in Section 2.2, Bask and Melkersson (2003a) are able to more formally introduce bootleg cigarettes into a theoretical framework. ${ }^{7}$ The model is then tested on annual Swedish time-series data for the period 1964-2001, covering the markets for legal and bootleg cigarettes. In general, the model works well for describing bootleg cigarette demand, while it does not work at all for legal cigarette demand. A stable result is that legal cigarette demand is negatively related to price, while bootleg cigarette demand is independently or positively related to the legal price. This indicates, as expected, the drawback for using excise duty on legal cigarettes since this attracts more agents into the market for bootleg cigarettes.

\subsection{The interdependence between different addictive goods}

Based on the rational addiction model of multiple addictive goods, developed in principle in Section 2.2, Bask and Melkersson (2003b) use aggregated annual data for the period 1955-1999 to analyze the

\footnotetext{
7 The model in Section 2.2 is modified to specifically consider legal and bootleg cigarettes. For more technical details, see Bask and Melkersson (2003a). Note that since the authors do not have access to information on the price of illegal cigarettes, this price is replaced by the price of legal cigarettes.
} 
interdependence between drinking and cigarette smoking in Sweden. They first estimate demand for alcohol and cigarettes as separate equations and find that alcohol demand is quite well described by the rational addiction model, while the same is not true for cigarettes. ${ }^{8}$ The long-run own-price elasticities are negative, and alcohol demand is more elastic, i.e., more sensitive to a change in price, than cigarette demand. The long-run cross-price elasticities are also negative, showing that alcohol and cigarettes are complements, which indicates that an increase in cigarette smoking contributes to increased use of alcohol.

The empirical specification by Goel and Morey (1995) allows for addiction but not rationality. Using U.S. state-level data for the period 1959-1982, demand equations for cigarettes and liquor are estimated separately and their interdependence is allowed through cross-price effects. The regression results show that cigarettes and alcohol are substitutes in consumption, which is in contrast to the results by Bask and Melkersson (2003b). Chaloupka and Laixuthai (1997) use micro-level data of high school seniors from the Monitoring the Future survey (MTF) for 1982 and 1989 to estimate demand equations for alcohol, marijuana and "other drugs". The model does not allow for addiction, but the goods are interdependent through cross-price effects. Still, the results suggest that alcohol and cigarettes are substitutes.

Pacula (1997) proposes a theoretical model for a situation with multi-commodity habit formation. The model allows for testing of a joint habit stock of the addictive consumption goods as well as rationality. Pacula (1998b) includes estimation of demand for alcohol and marijuana, where the goods are allowed to interact through cross-price effects in individual-level demand equations. Using data from the National Longitudinal Survey of Youth (NLSY) in the U.S., she finds, in contrast to some other work, a negative and significant effect implying complementarity between the use of alcohol and marijuana. ${ }^{9}$ Pacula (1998b) asserts that the difference probably lies in the individual-level demand functions estimated, which can be compared to other studies on U.S. data where more aggregated data are used. Based on annual state aggregated data from the MTF for the period 1980-1989, DiNardo and Lemieux (1992) find that alcohol and marijuana are substitutes. This is also in line with their more recent study, Chaloupka and Laixuthai (1997).

Decker and Schwartz (2000) estimate empirical specifications of the demand for alcohol and cigarettes in a cross-section data set, which consists of individual-level data from the Behavioral Risk Factor Surveillance System (BRFSS) between 1985 and 1993. The goods are interdependent through cross-price effects. According to the results, there is complementarity in the consumption of alcohol and cigarettes with respect to alcohol prices. When looking at cigarette prices, the own-price effect is negative, as expected, but the cross-price effect on alcohol consumption is positive, suggesting that the goods are substitutes with respect to cigarette prices.

Using cross-section data, Su and Yen (2000) analyze the demand for cigarettes, beer and wine, respectively, with special focus on non-participation, i.e., zero consumption levels. Interdependence between the

\footnotetext{
8 This result may be compared with Bask and Melkersson (2003a), who found that the demand for bootleg cigarettes is well described by the rational addiction model.

9 Kandel and Maloff (1983) and Ellickson and Hays (1991) also find complementarity between alcohol and marijuana.
} 
three addictive consumption goods is discussed in the text and all three goods are estimated simultaneously, but no direct cross-price and cross-product effects are included in the demand equations. Farrelly et al. (2001) estimate the demand for cigarettes and marijuana allowing for cross-price effects (a proxy for the marijuana price is used). Data for the period 1990-1996 originate from the National Household Survey on Drug Abuse (NHSDA), which is a survey of the drug habits of the non-institutionalized U.S. population aged 12 and older. In line with Pacula (1998b) and Chaloupka et al. (1999), Farrelly et al. (2001) find that tobacco and marijuana are complements.

Based on a general multi-commodity habit formation theory, Pacula (1998a) studies the demand patterns of alcohol and marijuana by youth and young adults in the U.S. Data originate from the 19831984 NLSY. According to the results, higher beer prices reduce the demand for alcohol and marijuana, which suggests that there is complementarity in the demand for the two goods. She also finds that the use of alcohol and cigarettes seems to be a gateway into the use of marijuana. van Ours (2001) use a Dutch cross-section data set to analyze the use of alcohol, cannabis, cocaine and tobacco, with a special focus on gateway effects of addictive goods. When accounting for individual heterogeneity, van Ours (2001) does not find any evidence of soft drugs serving as stepping stones to hard drugs.

\section{The usefulness of economic theory}

The consumption of addictive goods fascinates a large population of the research community, and one would perhaps not think about economics as the main discipline for studying addiction. However, there is an upsurge of economics papers on this topic. The most widely accepted theoretical framework is the rational addiction model, and the purpose of this paper is to present the multiple-good extension of the model, and discuss its empirical relevance.

For many goods, the price is an important decision variable for an individual choosing what amount of the good to consume. For example, a lower price on vehicles (all other things equal) may increase the sales of cars. The actual extent of increase is determined by the price elasticity of the good. The price elasticity varies for different goods. For instance, we may expect a high price elasticity on vehicles. On the other hand, it is reasonable to believe that the price elasticity is lower, or even very low, for dairy products since these products are basic daily consumption goods.

But what about the demand for cocaine, heroin and marijuana? In conformity with conventional wisdom, the consumption of these addictive substances is not responsive to price. According to the rational addiction model and the empirical results, prices do matter for the decision on how much of the addictive good to consume. Thus, the model and the empirical results appear to contradict conventional wisdom.

The multiple-good extension of the rational addiction model is developed in order to investigate, for example, whether a less harmful good like moist snuff contributes to less or more smoking. In other 
words, should one encourage the use of moist snuff in smoking cessation programs? Bask and Melkersson (2003c) investigate this issue, and give an answer in the negative. The reason is that cigarettes and moist snuff are complements in consumption.

Further, should one discourage smoking by increasing the tax on cigarettes? According to Bask and Melkersson (2003a), the answer is no. The reason is that neglecting the bootleg market hides the fact that price sensitivity is not entirely a consequence of people smoking less or quitting smoking altogether when prices increase, but rather is partly explained by the fact that bootleg cigarettes are substituted for some legal cigarettes. From the point of view of policy implications, it is therefore crucial to include the markets for both legal and bootleg cigarettes in the analysis.

The empirical literature shows that some of the results regarding the rational addiction hypothesis, are sensitive to the data set used. However, one should not be too hasty in rejecting the hypothesis that consumers behave rationally when consuming addictive goods. The model is based on utility maximization of a representative consumer. This may not be appropriate if the agents are heterogeneous. Consumption of, for example, cigarettes at one particular point in time is the result of a complex flow of actions on the part of individuals who start smoking, quit smoking and alter their consumption levels. Moreover, the consumption of a harmful good may affect individuals differently. Some individuals develop addiction easily, while other individuals may consume the same level of the good year after year, but are still not addicts. Hence, there is a connection between personality and the use of an addictive good.

Since the consumption of addictive goods often leads to extra costs beyond the cost of the good itself, not only for the consumer but also for society in general, policy implications are of major interest. A good theoretical foundation for these implications does, therefore, strike as important. We hope, and believe, that the multiple-good extension of the rational addiction model described in this paper can be useful for this matter, and for studying different combinations of addictive consumption goods.

\section{References}

Bask, M. and Melkersson, M. (2003a). Rational Addiction and Cigarette Smoking in the Presence of Bootleg Cigarettes. Working Paper, Umeå University.

Bask, M. and Melkersson, M. (2003b). Rationally Addicted to Drinking and Smoking? Forthcoming in the Applied Economics.

Bask, M. and Melkersson, M. (2003c). Should One Use Smokeless Tobacco in Smoking Cessation Programs? A Rational Addiction Approach. Forthcoming in the European Journal of Health Economics.

Becker, G. S., Grossman, M. and Murphy, K. M. (1994). An Empirical Analysis of Cigarette Addiction. American Economic Review, 84, 396-418.

Becker, G. S. and Murphy, K. M. (1988). A Theory of Rational Addiction. Journal of Political Economy, 
96, 675-700.

Chaloupka, F. J. and Laixuthai, A. (1997). Do Youths Substitute Alcohol for Marijuana? Some Econometric Evidence. Eastern Economic Journal, 23, 253-276.

Chaloupka, F. J., Pacula, R. L., Farrelly, M. C., Johnston, L. D., O’Malley, P. M. and Bray, J. W. (1999). Do Higher Cigarette Prices Encourage Youth to Use Marijuana? National Bureau of Economic Research, Working Paper No. 6939.

Chaloupka, F. J. and Warner, K. E. (2000). The Economics of Smoking. In Culyer, A. J. and Newhouse, J. P., eds., Handbook of Health Economics, Volume 1B, Ch. 29, North-Holland.

Cook, P. J. and Moore, M. J. (2000). Alcohol. In Culyer, A. J. and Newhouse, J. P., eds., Handbook of Health Economics, Volume 1B, Ch. 30, North-Holland.

Decker, S. L. and Schwartz, A. M. (2000). Cigarettes and Alcohol: Substitutes or Complements? National Bureau of Economic Research, Working Paper No. 7535.

DiNardo, J. and Lemieux, T. (1992). Alcohol, Marijuana, and American Youth: The Unintended Consequences of Government Regulation. National Bureau of Economic Research, Working Paper No. 4212.

Ellickson, P. and Hays, R. (1991). Antecedents of Drinking Among Youth Adolescents with Different Alcohol Use Histories. Journal of Studies on Alcohol, 52, 398-408.

Farrelly, M. C., Bray, J. W., Zarkin, B. A. and Wendling, B. W. (2001). The Joint Demand from Cigarettes and Marijuana: Evidence from the National Household Surveys on Drug Abuse. Journal of Health Economics, 20, 51-68.

Ferguson, B. S. (2000). Interpreting the Rational Addiction Model. Health Economics, 9, 587-598.

Galbraith, J. W. and Kaiserman, M. (1997). Taxation, Smuggling and Demand for Cigarettes in Canada: Evidence from Time-Series Data. Journal of Health Economics, 16, 287-301.

Goel, R. K. and Morey, M. J. (1995). The Interdependence of Cigarettes and Liquor Demand. Southern Economic Journal, 62, 451-459.

Kandel, D. and Maloff, D. (1983). Commonalities in Drug Use: A Sociological Perspective. In Levinson, P., Gerstein, D. and Maloff, D., eds., Commonalities in Substance Abuse and Habitual Behavior, Lexington Books.

Meier, K. J. and Licari, M. J. (1997). The Effect of Cigarette Taxes on Cigarette Consumption, 1955 Through 1994. American Journal of Public Health, 87, 1126-1130.

Melkersson, M. (2002). Smoking Habits and Quitting Costs in the Presence of a Close Substitute. Working Paper, SOFI, Stockholm University.

Ohsfeldt, R. L., Boyle, R. G. and Capilouto, E. (1997). Effects of Tobacco Excise Taxes on the Use of Smokeless Tobacco Products in the USA. Health Economics, 6, 525-531.

van Ours, J. C. (1995). The Price Elasticity of Hard Drugs: The Case of Opium in the Dutch East Indies, 1923-1938. Journal of Political Economy, 103, 261-279. 
van Ours, J. C. (2001). On the Dynamics in the Consumption of Alcohol, Tobacco, Cannabis and Cocaine. Working Paper, Tilburg University.

Pacula, R. L. (1997). Economic Modelling of the Gateway Effect. Health Economics, 6, 521-524.

Pacula, R. L. (1998a). Adolescent Alcohol and Marijuana Consumption: Is There Really a Gateway Effect? National Bureau of Economic Research, Working Paper No. 6348.

Pacula, R. L. (1998b). Does Increasing the Beer Tax Reduce Marijuana Consumption? Journal of Health Economics, 17, 557-585.

Showalter, M. H. (1999). Firm Behavior in a Market of Addiction: The Case of Cigarettes. Journal of Health Economics, 18, 409-427.

Su, S.-J. and Yen, S. T. (2000). A Censored System of Cigarette and Alcohol Consumption. Applied Economics, 32, 729-737.

Sung, H.-Y., Hu, T.-W. and Keeler, T. E. (1994). Cigarette Taxation and Demand: An Empirical Model. Contemporary Economic Policy, 12, 91-100.

Suranovic, S. M., Goldfarb, R. S. and Leonard, T. C. (1999). An Economic Theory of Cigarette Addiction. Journal of Health Economics, 18, 1-29.

Tilashalski, K., Rodu, B. and Cole, P. (1998). A Pilot Study of Smokeless Tobacco in Smoking Cessation. American Journal of Medicine, 104, 456-459. 
Table 1: Empirical studies on various addictive consumption goods

\begin{tabular}{|c|c|c|c|c|}
\hline Author & Period & Data & Addictive goods & Interdependence \\
\hline DiNardo and Lemieux (1992) & $1980-1989$ & $\begin{array}{l}\text { U.S. MTF; } \\
\text { state aggregated }\end{array}$ & $\begin{array}{l}\text { Alcohol, } \\
\text { marijuana }\end{array}$ & Substitutes \\
\hline Chaloupka and Laixuthai (1997) & 1982,1989 & $\begin{array}{l}\text { U.S. MTF; } \\
\text { individual-level }\end{array}$ & $\begin{array}{l}\text { Alcohol, } \\
\text { marijuana }\end{array}$ & Substitutes \\
\hline Pacula (1998a) & $1983-1984$ & $\begin{array}{l}\text { U.S. NLSY; } \\
\text { individual-level }\end{array}$ & $\begin{array}{l}\text { Alcohol, } \\
\text { marijuana }\end{array}$ & Complements \\
\hline Pacula (1998b) & 1979,1984 & $\begin{array}{l}\text { U.S. NLSY; } \\
\text { individual-level }\end{array}$ & $\begin{array}{l}\text { Alcohol, } \\
\text { marijuana }\end{array}$ & Complements \\
\hline Chaloupka et al. (1999) & $1992-1994$ & $\begin{array}{l}\text { U.S. MTF; } \\
\text { individual-level }\end{array}$ & $\begin{array}{l}\text { Cigarettes, } \\
\text { marijuana }\end{array}$ & Complements \\
\hline Farrelly et al. (2001) & $1990-1996$ & $\begin{array}{l}\text { U.S. NHSDA; } \\
\text { individual-level }\end{array}$ & $\begin{array}{l}\text { Cigarettes, } \\
\text { marijuana }\end{array}$ & Complements \\
\hline Goel and Morey (1995) & 1959-1982 & $\begin{array}{l}\text { U.S.; } \\
\text { state aggregated }\end{array}$ & $\begin{array}{l}\text { Alcohol, } \\
\text { cigarettes }\end{array}$ & Substitutes \\
\hline Decker and Schwartz (2000) & $1985-1993$ & $\begin{array}{l}\text { U.S. BRFSS; } \\
\text { individual-level }\end{array}$ & $\begin{array}{l}\text { Alcohol, } \\
\text { cigarettes }\end{array}$ & $\begin{array}{l}\text { Complements in } P_{A} \text {, } \\
\text { Substitutes in } P_{C}\end{array}$ \\
\hline Bask and Melkersson (2003b) & 1955-1999 & $\begin{array}{l}\text { Swedish aggregated } \\
\text { time-series }\end{array}$ & $\begin{array}{l}\text { Alcohol, } \\
\text { cigarettes }\end{array}$ & Complements \\
\hline Ohsfeldt et al. (1997) & 1985 & $\begin{array}{l}\text { U.S. CPS; } \\
\text { individual-level }\end{array}$ & $\begin{array}{l}\text { Cigarettes, } \\
\text { snuff }\end{array}$ & Substitutes \\
\hline Bask and Melkersson (2003c) & $1964-1997$ & $\begin{array}{l}\text { Swedish aggregated } \\
\text { time-series }\end{array}$ & $\begin{array}{l}\text { Cigarettes, } \\
\text { snuff }\end{array}$ & Complements \\
\hline
\end{tabular}

